\title{
NOTAS SOBRE A GLOBALIZAÇÃO DA ECONOMIA E O ESTADO*
}

\begin{abstract}
M. L. Malagutit"
"[E necessámo construir] uma abordagem que se esforce por analisar; metodicamente. as consequéncias devastadoras dessas polificas neoliberais que, agora, estão sendo aplicadas internacionalmente. inclusive nos paises sul-americanos". J. Habermas, 1995.
\end{abstract}

\section{GLOBALIZAÇĀO, INTELLIGENTZIA E PODER}

Considerando ultrapassados os projetos de desenvolvimento econômico baseados nas particularidades nacionais, nas especificidades culturais e históricas dos povos, boa parte dos economistas e analistas da economia internacional tendem a aceitar acriticamente um conjunto de práticas econômicas cujo caráter pretensamente neutro ou pragmático permitina sua adoção em qualquer parte do mundo

Esta opção pelo pragmatismo é um fenômeno relativamente recente. Ela reflete um dos aspectos fundamentais da crise estrutural por que passa a organização capıtalista mundial desde meados dos anos 1970 . Em função da elevaçào dos niveis de desemprego, da insegurança ocupacional e da exclusão social que, real ou imaginariamente, tende a se expandir $\mathrm{e}$ atingir a "intelligentzia" dos diversos paises, o pragmatismo passou a representar uma espécie de estratégia de sobrevivência adotada pela maioria dos cientistas sociais. Se num primeiro momento -

A elaboração deste ensaio foi estimulada por uma palestra proferida na Universidade Federal do Espírito Santo em abril de 1995 Agradeço aos aluros de graduação em economja (a quem esta palestra foj dirigida) e err especial à Profa. Elivan Rosas Ribeiro, cuja crítica penetrante levou-me a rever algumas opjniões.

Prof. do Mestrado em Econonia da Universidade Federal da Paraiba (Campus

In) Doutor em Economia pela Universidade de Picardie, Amıens, França.

Rev. Raizes. Campma Grande, Ano .17!" " II, pp.65-84, Jumho 1995. 
finais dos anos 70 até meados dos anos 80 - apenas os segmentos menos privilegiados da classe trabalhadora foram atingidos pelos efeitos da recessão, já de 1985 a 1995 a crise também atinge duramente as camadas melhor remuneradas do salariado regular ou estabelecido: empregados de grandes empresas privadas e públicas, assim como 0 funcionalismo público. Neste segundo momento, a "intelligentzia", as elites intelectuais, vêm ruir alguns de seus "privilégios" econômicos e, concomitantemente, verificam a pouca repercussão dos seus discursos numa sociedade assolada por uma "ofensiva conservadora neoliberal [que não estimula] um maior radicalismo nas demandas sociais" ${ }^{n 1}$.

O pragmatismo parece representar, então, uma postura intelectual "anti-cíclica", uma estratégia de sobrevivência, cuja generalização efetiva-se ao longo dos anos 1980-90. Embora, como é sabido, a capitulação definitiva dos intelectuais, ou a vitória do pragmatismo, tenha se consolidado apenas em 1989 - quando do desmantelo do socialismo real. $\mathrm{Na}$ realidade, porém, este foi apenas o "estopim" da renúncia, o pretexto necessário ao abandono - até aqui velado - das antigas pretensões cognitivas de boa parte da intelligentzia. Nas palavras de Habermas, "Desde o fim da União Soviética, parece ter se difundido no mundo inteiro o pressuposto tácito de que, com isso, toda a tradição socialista e os argumentos críticos e cépticos com relação ao capitalismo teriam perdido seu valor ${ }^{H 2}$. Ou seja, imediatamente após a queda do muro, intelectuais do mundo inteiro ratificam sua opção pelo senso comum quotidiano.

Faz-se necessário, no entanto, evitar as generalizações abusivas. Embora a renúncia ao pensamento social crítico seja uma característica

\footnotetext{
${ }^{1}$ Dos Santos, $\mathrm{T}$. "Fernando Henrique Cardoso e a Teoria da Dependência" in Política e Administração, FESPERJ, V. 2, $\mathrm{n}^{\mathrm{o}} 4,1994$, p.69. Embora o autor tenha se referido especificamente ao caso brasileiro, a "ofensiva conservadora neoliberal" é um fenômeno que, com poucas nuances, pode ser generalizado ao capitalismo ocidental como um todo. Consulte-se, por exemplo, Marques-Pereira, J. Marché du Travail, Protection Sociale et Développement à I'Heure de la Globalisation: Un Jeu de Miroirs (Europe/Amérique Latine), contribuição ao Seminário sobre o Método da Regulação, Fundap, São Paulo, de 4 a 6 de abril de 1995.

${ }^{2}$ J.Habermas, Folha de São Paulo, Cademo Mais! de 30 de abril de 1995.
} 
atual da untelligentzia nuundial, suas manifestações diferem segundo a categoria de intelectual considerada. Aceitando-se uma classificação certamente grosseisa - que divide os intelectuais entre "orgânicos" (Gramsci) e "flutuantes"' (Mannheim), percebemos entre os orgânicos progressistas una atitude cínica e céptica frente às possibilidades de implementação de reformas sociais populares. Embora suas crenças e seus ideais mantenham-se inabalados, eles distanciam-se dos grupos de pressão organizados, dos partidos e dos sindicatos, e encastelam-se nas universidades e institutos de pesquisa. Os intelectuais orgânicos consenvadores, por sua vez, deixam claras (mais do que nunca) suas preferências e engajantentos políticos: suas idéjas sendo largamente dominantes, uma maior aproximação com o poder político e a midia tomase inevitável.

Os intelectuais "livremente flutuantes" (em geral antigos simpatizantes de uma esquerda independente, apartidária), por outro lado, deixam o cinismo e o ceticismo desaguar numa prática social fundamentada na desilusão, na resignação e no oportunismo. o pragmatismo. Em outras palavras: abandonando uma postura social critica, estes intelectuais "flutuantes" transformam-se em meros técnicos, gestores da coisa privada ou tecnoburocratas nos vários escalões govemamentais. Com este procodimento, recuperam algumas das vantagens econômicas do periodo pré-crise e, ao mesmo tempo, colocam em prática uma nova ideologia, uma ideologia da moda: o pragmatismo. En coerência com a renúncia da transformação pelas idéias, perden a fé na razão e no homem Mais precisamente: como cinicos e cépticos, eles renunciam à reflexão crítica. Já como oportunistas, eles elegem o Mercado - força impessoal, objetiva e aparentemente neutra - como substituto da razão e motor da dinâmica social ${ }^{s}$

\footnotetext{
${ }^{3}$ Visceralmente ligados a uma classe social. Militantes políticos engajados exa partidos, sindıcatos ou organizações ideologicamente definidos

${ }^{1}$ Livres pensadores. Jdeologicamente instáveis e cientificamente indisciplinados.

5 Theotonio dos Santos detecta lucidamente esta renúncia ao conheciniento quando analjsa o pensamento de Femando H. Cardoso e o da "intelectualidade de esquerda" que preenche os primcipais cargos de seu govemo. "Mas não se pode permitir que um pragmatismo sem propostas, de origem direitista e conservador, se imponha em
} 
Com o encastelamento dos intelectuais orgânicos progressistas, o que hoje podemos chamar de esquerda ativa resume-se (ou quase) aos antigos intelectuais "flutuantes", agora ocupando os primeiros níveis da burocracia estatal e difundindo o pragmatismo mercantil como prática política. Doravante, os ideais conservadores defrontam-se apenas com as imposições do mercado, tradicionalmente em harmonia com estes mesmos ideais: é a sentença de morte do confronto de idéias, do políti$c o$, da discussão e da dialética. Mas quando os confrontos conscientes desaparecem, ou melhor, são proscritos, é lavrada a sentença de morte da democracia. Neste sentido, a tecnoburocracia estatal de "ideologia" pragmática personaliza uma ditadura, a ditadura das forças inconscientes do mercado.

A partir deste momento, as leis objetivas do mercado parecem substituir as idéias e a razão. Além de seu papel econômico, as oscilações da oferta e da procura, assim como os critérios de eficiência, teriam passado a decidir, tanto o que é científico, quanto "politicamente correto". Se os interesses de determinados grupos sociais concordam com as tendências do mercado, eles são politicamente corretos e cientificamente justificáveis. Caso contrário, representam interesses atrasados e corporativistas. Ora, opor-se às leis cegas do mercado ou tentar conter a globalização da economia, dizem os neoliberais, é remar $1^{9}$ ) contra uma tendência histórica irreversível $\mathrm{e}^{2}$ ) contra a modernidade ${ }^{6}$.

Subordinando-se à autoridade do mercado, os globalistas "esquecem" que a história humana não tem destino nem finalidade, e que as leis sociais apenas tendem a ser irreversíveis nos periodos ditatoriais. Nas democracias, por outro lado, o que hoje parece irreversível, amanhã pode ser alterado pela vontade grupal ou pela consciência coletiva. No que diz respeito à modernidade, não há porque acreditarmos

detrimento da verdade científica". Dos Santos, op. cit. p. 72 .

${ }^{6}$ Marques-Pereira ressalta que o início da recessão mundial "inaugurou uma crise do desenvolvimento que geralmente se associa às reestruturações impostas pela globalização da economia. Estas são consideradas [pelos globalistas] como um dinâmica irreversivel que faria tocar o sino de finados das formas de organização econômica e do papel do Estado (...)". Op. cit. p.2. 
que a estrita obediência à lógica do mercado é o caminho mais curto para alcança-la Se mais não fosse, porque não existe un consenso minimo sobre a sua definição. No que consiste a modemidade? A ciência social não nos oferece uma resposta. No máximo, ficamos sabendo que existcm várias "modemidades", cada uma localizada num ponto especifico da linha do tempo: os descontentes românticos pernsam descortiná-la "em algum lugar do passado". Os descontentes pragmáticos, na realidade presente dos paises do $1^{\circ}$ mundo. Os descontentes oprimidos, por sua vez, "em algum lugar do futuro". O fato é que a modemdade, como criação humana, é tão segmentada quanto a sociedade. Logo a modernidade (como contexto social singular) só pode existir numa sociedade artificialmente homogeneizada. Num sistema social pasteurizado por leis que, sem deixarem de ser sociais, como as do mercado, resultam numa dinâmica societária independente das vontades específicas dos distintos segmentos da sociedade. Mas que tipo de sociedade pode estimular a participação inconsciente (como zumbis...) de seus integrantes? Que tipo de sociedade pode aceitar que "os homens se encontrem constantemente frente aos resultados de seus próprios atos como o aprendiz de feiticeiro que após invocar os gênios não sabe como controlá- $\operatorname{los}^{7}$ "? Que tipo de regime politico pode dirigi-la? Não é dificil concluir que a sujeição irrestrita e irrefletida às leis do mercado gera uma sociedade apática, impotente frente aos seus próprios problemas, pois entendidos como designios ou males inevtáveis. Uma sociedade que, se injusta, tende a conservar-se como tal; se composta por pobres e ricos, tende a perpetuar a pobreza de uns e a riqueza de outros; se composta por fortes e fracos, tende a fundamentat-se no poder do medo e da força (Hobbes).

Fica claro, pois, que na medida em que aceitamos como inevitáveis as orientações soctais do mercado, nos afastamos dos fundamentos iluministas da demociacia modema Devenos aceitar, então, que a força institui o direito, a obediência transforma-se em dever e o Estado democrático reflete o direito dos mais fortes

Por outro lado, a recusa ao neoliberalismo fortalece o tecido so-

'Elias, N La Sociéte des Individus. Paris, Fayard, 1991, p. 107. 
cial. $\mathrm{Na}$ medida em que rejeitamos a força e todos os despotismos (o religioso ou o do mercado, por exemplo) como fundamentos do Estado de direito, elegemos em seu lugar a Razão e a Convicção. Segundo um dos mais ilustres iluministas, todo direito fundamentado na força não passa de um contra-senso, pois "desde que a força faz o direito, o efeito toma o lugar da causa, pois toda força que sobrepujar a primeira sucedê-la-á nesse direito. Desde que se pode desobedecer impunemente, torna-se legítimo fazê-lo e, visto que o mais forte tem sempre razão, basta somente agir de modo a ser o mais forte. Ora, que direito será esse que perece quando cessa a força? Caso se imponha obedecer pela força, não se tem necessidade de obedecer por dever, e, se não se for mais forçado a obedecer, já não se estará mais forçado a fazê-lo. Vê-se, pois, que a palavra direito nada acrescenta à força - nesse passo, não significa absolutamente nada" ${ }^{\prime \prime}$.

Mas que o leitor nos entenda bem. Não estamos aqui fazendo a apologia do Estado de direito. Se no século XVIII a "ingenuidade" de Rousseau era legítima, hoje ela é inaceitável. $O$ pensamento de Hobbes (direito derivado da força) é, inegavelmente, muito mais realista. Mas não é por isso que devemos aceitá-lo, ao contrário! Render-se ao estabelecido é exatamente o que fazem os pragmáticos. Assim, se a globalização e as práticas neoliberais são dominantes, devemos questionálas, influencia-las nos seus contornos e, se possível, adaptá-las à modernidade aspirada pela maioria, pelos oprimidos.

Na modernidade dos oprimidos o Estado de direito deve ter instituições fortes, responsabilidades sociais e culturais bem definidas, deve permitir a expressão dos anseios populares e, principalmente, manter um diálogo constante com a sociedade organizada e consciente. Caso contrário, isso seria abrir o caminho para um questionamento do sufrágio universal (expressão subjetiva da vontade popular), para a transformação de legítimos interesses eleitorais em meros pleitos eleitoreiros e, enfim, para a radical desmobilização da sociedade civil $^{9}$.

\footnotetext{
${ }^{8}$ Rousseau, J, J. Do Contrato Social (ou principios do direito politico), São Paulo, Abril, 1978 (coleção "Os Pensadores"), pp. 25-26.

${ }^{9}$ Isso é o que temos presenciado nos EUA, na França ou no Brasil. Nestes paises as
} 
Já em 1944, criticando os opositores do "welfare state" (Estado do bem-estar), Polanyi percebia uma ligação íntima entre a ideologia do mercado livre e a negação da humanidade Este mestre da antropologia econônica afirmava que o importante é acabar, de uma vez por todas, com esta aberração que é a utopia do mercado livre, para isso restaurando as salvaguardas necessárias para que as forças do mercado não continuem a destruir a natureza e a própria humanidade ${ }^{10}$.

Durante 3 décadas a reivindicação de Polanyi (e de diversos intelectuais progressistas) pareceu ter se consolidado. Os govemantes e as elites pareciam ter entendido que a própria estabilidade da organização capitalista dependia de uma sére de freios às leis cegas do mercado. Neste sentido, a miséria, as condições de trabalho e o desemprego passaram a ser concebidos como inerentes ao funcionamento da sociedade e, portanto, de responsabilidade do Estado.

Hoje, no entanto, as conquistas sociais destas 3 décadas estão ameaçadas. Governantes e intelectuais govemistas renegam a responsabilidade pública sobre os problemas sociais. Sob esta ótica, os individuos senam pobres porque ineficientes, estariam desempregados porque preguiçosos ou, talvez, inadaptados. Ao propor-se a subordinação do Estado ao Mercado, a cidadania à lei do mais forte, a democracia ao darwinismo social, é a própria humanidade - como diz Polanyi - que está sendo questionada No que diz respeito ao desemprego, por exemplo, é a sociedade-economia perversa de Afred Marshall que aqui recupera o espaço ideológico deixado por Keynes. Segundo Marshall, no espaço liberal o indivíduo sem emprego não deve merecer nenhuma atenção especial das instituições públicas, embora deva ser alvo de uma "observação bem intencionada, mas severa"1". Além de recusar toda

políticas neoliberais têm subordinado a sociedade política e a civil a uma vontade impessoal única, ditada pelo mercado e acomodada socialmente pela tecnoburocracia composta de intelectuais "flutuantes" (o neoliberalismo de Regan e Balladur, os planos Cruzado, Collor e Real da FGV/PUC etc.).

${ }^{10}$ Citado por Christian Topaiov in Topalov, C. Naissance du Chômeur. Paris, Albin Miclsel, 1995, pp.26.27.

${ }^{11}$ Carta de Alfred Marshall à Percy Alden (28 de janeiro de 1903) in Marshall. A. Memorials of Alfred Marshall, Londres, ed. A C. Pigou. 1925, pp.446/447. 
responsabilidade pública sobre o desemprego, o Estado marshaliano o atribui a uma deficiência individual e a-social, que deve ser punida com sevendade e vigilância ${ }^{12}$.

\section{GLOBALIZAÇĀO E DETERMINISMO ECONÓMICO}

Segundo os globalistas, o processo de globalização implica tanto numa autonomização do mercado em relação ao Estado, quanto num enfraquecimento das especificidades/identidades nacionais: no mundo global a economia ditaria as politicas publicas que, por sua vez, moldariam as culturas $e$ as identidades regionais. Neste sentido, o econômico conteria em si mesmo todas as detenninações do social. A transformação das formas de produção e troca provocaria um movimento indomável e irresistivel de adaptação da sociedade às novas necessidades do mercado capitalista. Não estariamos longe, então, da consagração do que Palloix chamou de "pretensão totalitária do econômico" 13

Vejamos mais de perto esta questão

A perspectiva neoliberal afirma que a eliminação de todos os entraves à livre circulação do capital provocaria uma 1) livre circulação do capital e da mão de obra, una 2) distribuição espacialmente homo-

\footnotetext{
${ }^{12}$ Nurm belo escrito de 1926, Keynes caracteriza o funcionamento da sociedade marshaliana como "um estado de coisas no qual a distribuição ıdeal dos recursos produtivos pode ser conseguida através de individuos que agem de maneira independente, pelo método de ensaio a erro, de tal maneira que os individuos que se movimentam na direção correta destruirão, pe]a competição, aqueles que se movimentam na direção errada. Isto implica que não deve haver perdão ou proteção para os que empatam seu capital ou seu trabalho na direção errada. Este é um método para levar ao topo os negociantes melhor sucedidos, mediante uma luta cruel pela sobrevivencia, que seleciona os mais eficientes através da falência dos menos eficjentes. Não se leva em conta o custo da luta, mas apenas os lucros do resultado final, que se supōe serem permanentes. Como o objetivo é collher as folhas dos galhos mais altos, a maneira mais provável de alcança-lo é deixar que as girafas com pescoços mais longos façam morrer à mingula as de pescoços mais curtos". (Keynes, J. M. "O Fim do '"Laissez-Faire"', in Koynes, São Paulo, Ática, 1978, p. 106.)

${ }^{13}$ Palloix. C. La Sociéte Post-liconomique: Lsquisse d'ume Société dillernative. Paris, L'Harmattan, 1988.
} 
gênea dos bens e serviços ofertados e, enfim, uma 3) dissoluçāo das formas particulares/tradicionais de produção e distribuição. E com esta mobilidade do capital e do trabalho, verificar-se-ia uma equalização das taxas de lucro e das remunerações do trabalho a nivel mundial.

Esta indiferenciação econômica, no entanto, necessitaria de un certo espaço de tempo para se impor Num prmeiro momento, os capitais se dirgiriam para os Estados onde os salários (diretos + indiretos) e a tnbutação dos lucros fossem inferiores à média intemacional e, no campo politıco, uma relativa estabilidade institucional estivesse assegurada. A mão de obra, por sua vez, procuraria deslocar-se para os paises desenvolvidos, onde o movimento dos trabalhadores é organizado, os salános relativamente elevados a vigora um sistena de seguridade social eficiente.

Seguindo esta lógica de maximização das remunerações, observaríamos no médio e longo prazo à construção de um processo de homogeneização das caracteristicas econômicas dos Estados-nações. Em outras palavras, como resultado da livre circulação do trabalho e do capital presenciariamos uma nivelação mundial das condições de produção e da distribuição das riquezas. Neste sentido, a tradicional dicotomia entre o $1^{\underline{n}}$ e o $3^{0}$ mundo tenderia a desaparecer $O u$ seja, a própria idéia de um mundo dividido entre paises desenvolvidos e subdesenvolvidos perderia sua razão de ser.

No que diz respeito à gestão politica deste processo, a instauração de parlamentos internacionais (parlamento europeu, por exemplo) aparece, segundo as teses globalistas, como um momento essencial. Estes legislatıvos supra-estatais teriam como função precipua a resolução de diferendos ou de distorçōes observadas no exercicio das liberdades de deslocamento e de instalação, tanto da mão de obra quanto do capital: combate ao terrorismo (agora internacional), preservação do equilibno ecológico (evitar uma concentração excessiva de atividades produtivas poluentes, alocação geograficamente eqüitativa do lixo atômico. etc.), estabelccimento de uma legislação tributária e fiscal de transição, equiparação progressiva dos direitos sociais (aposentadorias, segurodoença, seguro-desemprego, auxilios-maternidade, sistema de saúde) etc 
No entanto, toda esta atividade politica de preparação, de acomodação das divergências, seria um desperdicio de tempo e trabatho caso não resultasse no estabelecimento da verdadeira âncora da globalização da economia a criação de uma moeda única.

Sem a instituição de uma moeda ínica, o processo de globalização não pode completar-se. A diversidade dos pólos de controle econômico ou a existência de múltıplas autoridades monetárias implicaria, sempre, $\mathrm{cm}$ políticas econômicas contraditórias ou em projetos de de senvolvimento divergentes. $\mathrm{O}$ aprofundamento do processo de globalização deve passar, pois, pela instauração juridico-política de um repre sentante único da nqueza mundial, pela instituição da moeda universal. Os parfamentos internacionais teriam, então, como tarefas primordiais, a cnação e a legitimação de uma moeda supra-estatal. Sob outro prisma, a legitimação de uma moeda única representaria o alicerce fundador de uma cidadania sócio-econômica também única, universal, preludiando, então, a dissolução dos próprios parlamentos (no plural) que the deram vida e, ao mesmo tempo, criando uma unica autoridade econômica murdial: concebidos como instituições preparatónas da unificação da economia mundial, os parlamentos internacionais decretariam sua própra dissolução ao instituírem a moeda sem fronteiras.

Superada assim a etapa da diversidade de poderes e de moedas, uma nova ordem politico-econômica mundial deveria assumir o lugar até hoje reservado às instituições do clássico Estado-nação Esta conclusão é encontrada, mais ou menos explicitamente, em todas as análises sobre a globalização da economia. Nestas percebe-se, claramente, a determinação do econômico sobre os restantes fenômenos sociais. A difusão internacional das condições de produção e de troca vigentes nos paises desenvolvidos crıana não apenas as formas sociais necessárias à sua expansão e equalização, como também substituiria as instituições politicas baseadas na nacionalidade por uma ordenação politica original, embora com contomos ainda indefinidos

Enquanto o poder dos Estados-nações subsistir na figura de suas moedas, na independência de suas ações monetárias e na utilização de seus recursos econômicos particulares, a estabilidade sistêmica do processo de giobalização, insistem os globalistas, não estará assegurada 
Jaques Delors, por exemplo, Deputado do Pariamento Europeu, elogia o sucesso do chanceler alenão $\mathrm{H}$. Kohl - presidente do Conselho Europeu - em convencer seus parceiros europeus sobre a existência de laços intimos entre uma "moeda única e a união politica". Laços que foram reconhecidos e concretizados no "tratado de Maastricht", conclui Delors ${ }^{14}$. Enquanto uma moeda única não estiver estabelecida, a uridade da economia mundial estará em conflito com a diversidade dos interesses regionais. E sem esta superação dos estreitos poderes dos Estados nacionais, dizem, a livre circulação de mercadorias será sempre uma utopia, a modemização das economias atrasadas uma quimera e a eliminação do subdesenvolvimento mais uma vez postergada.

Mais concretamente, a existência de moedas nacionais è identificada - corretamente - pelo grupo globalista como instrumento de afirmação de identidade e soberania nacionais. Da mesma forma que, ao contrário, uma moeda verdadeiramente universal aparece como um pressuposto fundamental - e também correto - da diluição das diferenças e da construção do cidadão do mundo. Caso este pressuposto não esteja presente, os globalistas alegam que alguns grupos tenderiam a fazer prevalecer seus interesses particulares sobre os da futura comunidade intemacional: poderiam conseguir taxas de juros subsidiadas para a implantação de projetos de interesse não-geral, obter facilidades de crédito para o escoamento de suas mercadorias individuais, proporcionar ganhos salanais reais para determinadas categorias de assalariados (nacionais ou regionais), estimular a passividade - ou a agressividade - de certas organizações dos trabalhadores etc. Enfim, estes grupos poderiam perpetuar a diferença em detrimento da uniformização, impedindo o movimento centripeto intrinseco à giobalização.

Enfim, a globalızação implıcana numa unidade de propósitos e de orientação econômucos que apenas a criação de unna autoridade econômica supranacional e forte podena legitimar. A superação dos interesses "egoístas" dos capitalismos nacionais precisaria - sempre segunda esta interpretação - de uma autoridade econônica que tenha

\footnotetext{
"Delors. J. "Le Croisé de l'Europe", in Le Nouvel Observatenr de I8-24 de maio de 199.5, p 17
} 
poder decisóno e instrumentos que assegurem o firme cumpnmento de suas decisões. Em resumo, a eliminação das rivalidades mesqunnlıas, que impedem o acesso de todas as economias à modemidade $e$ ao desenvolvimento, precisaria de um poder moderador, um poder que tenha como propósito transfornar a concorrência capitalista selvagen numa parcena estimulante, distribuindo eqüitativamente seus resultados pelas várias regiōes do capitalismo mundiai

"A integração comıptitiva dos paises em desenvolvimento na economia internacional liá de basear-se en vantagens comparativas dinânicas, con crescente incorporação do conhecimento ao processo produtivo A par do indispensável esforço interno de cada pais, este salto qualitativo pressupõe um ambiente internacional fundado na cooperação ${ }^{\text {is". }}$

Mas mesmo os globalistas não conseguem prever a complexa gama de funções que deverá exercer este poder supranacional quando de uma eventual globalização plena. Afirmam, no entanto, que ele deverá ter suas funções ampliadas na medida e na proporção em que avançar a integração mundial. Afirmam que esta autoridade deverá tomar decisões - e faze-las cumprir - sobre assuntos cuja relação com o processo produtivo è relativamente tênue. Por exemplo, para que os trabalhadores possam deslocar-se livremente não é necessário apenas abolir o uso de passaportes, vistos ou exigências financeiras: é preciso assegurar-lhes condições de trabalho homogêneas em todas as partes do mundo, condições de exercicio profissional reconheciveis e aceitáveıs, sejam eles trabalhadores ocidentais ou orientais.

O que os globalistas parecem não dar importância é que ao adentrar no terreno do "reconhecivel" e do "aceitável", o poder internacional em construção distancia-se consideravelmente do que tradicionalmente considera-se a "circunvizinhança" dos problemas econômicos. Há uma clara invasão dos dominıos — também tradicionais - da filosofia, da ética, da moral e da religião. Na realidade, a homogeneização das con-

\footnotetext{
${ }^{13}$ Discusso pronunciado na ONU por Celso Amorin, Chanceler brasileiro do governo ltamar Franco. Amorin, C. Folha de São Paulo. 27 de setembro de 1994, p. 1 (4). O grifo é nosso.
} 
dições de trabalho não pode ser uma tarefa meramente econômica (mesmo que o meramente econômico existisse): ela implica no nivelamento de raizes culturais que, submersas no inconsciente, impedem que os trabalhadores percebam uma mestna realidade de forma semelhante.

Mas como, então, levar a bom termo esta tarefa de conformação da memória dos povos? Por quais melos a neoliberalização da economia poderá produzir uma cultura universal? Não estaria subentendida nesta despreocupação neoliberal com as diferenças civilizatónas uma crença na onipotência (determinação) da economia? Como é possivel que paises como a China e o Brasil, por exemplo, com trajetórias históricas - e especificidades culturais - tão distintas possam chegar a possuir necessidades econômicas sinulares? Como é possivel submeter 1 (um) bilhão de muçuimanos ( $20 \%$ da humanidade) determinados a construir um Estado religioso, baseado na submissão feminina e nos preceitos do Corão, às tradiçōes e costumes ocidentais? Como, perguntamos, milhões de africanos serão convencidos a separar-se de suas culturas de subsistência e dos seus sistemas produtivos de hierarquia familiar, aceitando então as normas de "qualidade e produtividade" da indústria ocidental do primeiro mundo? ${ }^{16}$ A construção desta identidade universal não implicaria uma uniformização dos anseios e dos desejos dos povos, ou seja, as regacõos das especificidades nacionais forjadas pelas histórias passadas, das individualidades presentes e das personalidades futuras? Muito provavelmente, sim!

Mas é bom lembrarmos que a tentativa de modemização/uniformização das formas produtivas e culturais localizadas não é unla tarefa propriamente estranha ao capital. Durante séculos o capital europeu - com relativo sucesso - tentou substituir o artesanato pelo trabalho a domicilio, pela manufatura e pela indústria. Da mesma for-

\footnotetext{
${ }^{115}$ Num excelente estudo sobre as formas de produção na África, Morice nos relata a sua realidade econỏmica mais "modema", urbana: "Mesmo se nos detivermos ao meio urbano, sua extensão é tal que um observador inclinado aos raciocínios maniqueistas alı veria um modo mais apropriado de valorização para os capitalistas do - que o salariado". Agier, M., Copans, 3. \& Morice, A. Classes Ouvrières d'Afrigue Noire. Pans, Karthala - Orstom, 1987, p. 47.
} 
ma, a expulsão dos camponeses de seu habitat natural e a eliminação das culturas agricolas de subsistência conseguiram, com relativa facilidade, criar uma força de trabalho adaptada às necessidades do capital.

"Que ninguém se engane: o capitalismo não fica passivo em relação àquilo que the escapa. Trata-se de uma relação de força. F. Cooper mostra como o colonizador inglês perdia sua imaginação quando queria 'manter' inteiramente a força de trabalho indigena: ele se utilizava do 'compound', um lugar de aprisionamento e de controle que consagrava a separação do trabalhador e de sua familia. Os 'hostel' descritos por E. Webster, estes lares com seus poröes de forçados, configuram ainda hoje, na África do Sul, esta tentaçâo da classe capitalista a se apropriar do trabalhador, e não apenas do seu trabal ho" ${ }^{1}$.

No entanto, foi também este expansionismo do capital que criou os Estados-nações e consolıdou valores como "pátria", "raça", "religiāo", "classe" etc.. identidades e diferenças que têm servido de fator de urião, e mesmo de sutura, em casos extremos de fratura social. Apenas como exemplo, vale lembrar o caso da guerra das Malvinas que, unindo o povo em defesa da pátria, deu novo alento à ditadura argentina. De uma certa forma, podemos dizer que foi o próprio capital que cnou - quando the foi conveniente - as identidades e diferenças que hoje pretende suprimir. A questão que hoje se apresenta é se as politicas neoliberais terão forças para dissolver — agora que não thes convém - o que o próprio capital cultivou com carnho durante séculos. Um "carinho" tão grande que chegou a criar Estados artificiais (partilhas dos periodos pós-guerras mundiais), territórios sem nenhuma identidade, e que agora rebelam-se, dissolvem-se e guerreiam em nome de nacionalidades sufocadas, de religiōes perseguidas ou de raças discriminadas

Seria possivel, hoje, após estabelecidas estas identidades e diferenças, articular-se um programa de homogeneização de práticas produtivas, de concepções de autoridade e hierarquia, de particularidades estéticas e artísticas, anselos, angústias, desejos etc.? Nossa resposta é

\footnotetext{
"Ibden, p 10.
} 
provaveimente, não. A instituição do Estado-nação e a regulamentação politica da economia não são processos exteriores ao funcjonamento da economia. Após duas guerras mundiass, as políticas econômicas e as leis de mercado tomaram-se indissociáveis. Não é mais possivel pensar as políticas de Estado como um conjunto de intervenções em algo que lhes é estranho, extrínseco. Não é mais possivel pensar num Estado não-intervencionista que, diga-se de passagem, nunca existiu.

Chega mesmo a ser inconcebivel, por exemplo, que um Estado como o brasileiro, mais "enchuto" que o próprio Estado símbolo do neoliberalismo, o Estado Norte-americano, possa ser considerado como um dinossauro! ${ }^{18}$

"Foi assinı que o Estado brasileiro veio dar no estado a que chegamos, para dizer como o velho Aporelly O equilibrio monetário, a liberdade de iniciativa e a integração competitiva no mercado internacional são o único caminho para un país como o Brasil, que conta com enormes recursos, inclusive o mais escasso de todos - capacidade empresarial [sic]. Sendo a décima economia industrial do mundo e, já $76 \%$ urbana, não se pode permitir luxos de Albânia stalinista. Nosso pais não pode ficar como o último reduto dos dinossauros estatais..." ${ }^{19}$.

O Estado do bem-estar social, como diz Galbraith, "veio para fi$\operatorname{car}^{1120}$. Mas ele veio para ficar não só porque estabele um sisterna de segundade social para os trabalhadores, mas principalmente porque regula a concorrência inter-capitalistas (Banco Central, bancos estatais

${ }^{18}$ Participação do Estado na Economia (Anuário da ONU - 1991)

\begin{tabular}{|c|c|c|c|}
\hline Paises Desenv. & \% do Estado no PIB & Paises Subdesenv. & $\%$ do Estado no PIB \\
\hline Dinamarca & 51.96 & Bjasil & 21.44 \\
\hline Suécia & 49.78 & Costa Rica & 19.18 \\
\hline França & 42.10 & India & 16.76 \\
\hline E.U.A. & 28.14 & Etiópia & 16.21 \\
\hline
\end{tabular}

19 Campos, R. "Podemos não ser Parte do Mundo?", in Folha de São Paulọ de 13 de dezembro de 1994, p. 2 (2). (os grifos são nossos).

${ }^{20}$ Entrevista concedida a Follua de São Paulo em 09 de outubro de 1994, p. 6 (4) 
e nacionais de desenvolvimento, Tesouro Nacional, Superintendências de Desenvolvimento etc), cria demandas (obras públicas, forças armadas, funcionalismo público), especializa a força de trabalho (escolas $e$ universidades públicas), transmite os valores empresanais (concessões de rádio, televisāo etc.), controla a oferta de trabalhadores (legislação trabalhista, hospitais públicos, políticas demográficas etc.), defende a propnedade privada e faz valer os contratos (Policia, Justiça, tribunais, presidios, manicômios públicos etc.) etc., perenizando assim o sistema salarial. E por isso que ele veio para ficar. Uma ruptura artificial entre funções sociais (econômicas versus politicas) cuja comunhão viabiliza a sociedade do capital não interessa, no momento, a ninguém. Como colocou o sociólogo Carlos Alberto Dória, "deixada por si só, a sociedade regida pelo mercado pode degenerar em formas conhecidas [ou desconhecidas], como o fascismo ${ }^{21} "$. Neste contexto, globalização plena não corresponderia, efetivamente, à decretação do fim da história da humanidade, como enunciado por Polanyi? Nossa resposta é: muito provavelmente, sim.

Nossa tese é a seguinte: o gênero de violência observado na "açumulaçào primitiva" não será mais suficiente para impor as leis do capital, as leis do mercado capitalista. E isto porque, hoje, as leis do capital e o funcionamento dos Estados nacionais são indissociáveis. Após consolidados e resguardados os direitos à diferença, expressos nas Constituições de todos os Estados democráticos, a homogeneização da humanidade só poderá ocorrer pelo aniquilamento sumário dos movimentos sociais. Enfim, a consolidação do processo de globalização pressupõe - muito mais do que uma "acumulação primitiva" - a instituição de um poder politico com as prerrogativas que imaginamos possuir uma Ditadura Mundial

\section{CONCLUSÃO EM QUESTĀO}

Os globalistas argumentam que a equalização mundial das estru${ }^{21}$ Dójia, C A. "A Grande Transformação", in Folha de São Paulo de 03 de julho de
1994, p 6 (9) 
turas econômıcas conduz ao estabelecımento de umn novo espaço cultusal - juridico e político - no qual fomas alternativas de controle, regras de conduta e penalizaçào dos atores económicos deverão ser cruadas e sustentadas. Dada a universalidade civilizatóna crada pela globalızação, dizem, a nova configuração do poder político deverá afimar o seu distanciamento das nacionalidades e dos interesses "egoistas" de grupos específicos. Enfim, de uma maneira ou de outra, as formas culturais e os poderes politicos nacionais deverão ser, primeiro, enfraquecidos, depois, abolidos. Parece ser imprescindivel, então, a construção de uma configuração politica (e sócio-cultural supranacional) que possa normatizar e legitimar as fornas altemativas de convivência entre os atores sociais da futura economia globalizada.

No entanto, o mercado tem se expandido atè hoje sem uma efetiva unterferência de instâncias decisórias intemacionais. Desde o inicio do século XX vem se estabelecendo uma crescente interconexão entre as diversas economias nacionais. Hoje, mais do que nunca, sāo crescentes as possibilidades (potenciais) de investimentos nos paises desenvolvidos ou subdesenvolvidos, nas novas naçōes industrializadas da Aménca Latina ou do Onente, nos antigos territónos soviéticos, nas comundades primitivas da África ou nas regiōes desérticas do globo, no polo Sul ou no polo Norte: "assinı o europeu acorda cada manhã ligando seu rádio japonês e escutando os acontecimientos do nundo: erupções vulcânicas, terremotos, golpes de Estado, conferèncias internacionais, enquanto ele toma seu chá do Ceiläo, India ou China; elc mergulha numa banheira espumante de óleos do Taiti e utiliza uma loção após barba de fragrância exótica; ele coloca sua camisa feita com algodão do Egıto ou da Índia.. Seu relógio é suíço... A amadura de seu óculos é de tartaruga de Galápagos. "22 etc. etc. E não é apenas o cidadão do velho mundo desenvolvido que se encontra envolvido nesta teia de informações e de mercadorias "O africano na sua favela... está igualmente no circuito planetário. No seu cotidiano ele sofre os contragolpes do mercado mundial que afetam os cursos do cacau, do açucar, das

${ }^{22}$ Morin. E. Terre-Parrie. Paris, Seuil, 1993, p. 32. 
matérias primas que produz o seu pais ${ }^{23 "}$.

Além disso, os europeus votam pela unificação da Europa, Clinton funda o Nafta, o Cone Sul aplaude o Mercosul, os argentinos reelegem Menem e os brasileiros consagram Femando Hennque Cardoso: a mundialização e a politica neoliberal parecem merecer o consenso da opinião pública mundial ${ }^{24}$. Por que, então, se faz premente a criação de um poder à escala planetána? Por que a continuidade do processo de globalização precisa de um poder político altemativo?

A resposta parece estar no caráter agudo e duradouro da atual crise estrutural do capitalismo. Após 20/25 anos de crise, as sociedades capitalistas - desenvolvidas e subdesenvolvidas - estão mais do que nunca fragmentadas: a marginalidade social, a pobreza, a miséria absoluta, a concentração de rendas, a desılusão e a falta de perspectivas estão mais ou menos presentes em todas as economias. Ou nas palavras de Tavares: "A crítica à 'globalização' não está ainda suficientemente avançada, embora seus efeitos perversos, sobre o desemprego, concentração da senda, da nqueza e do saber, já comecem a manifestar-se com ma1s nitidez mesmo nos paises desenvolvidos"2s. Ao lado destes "efeitos perversos", percebe-se ainda uma nítida queda dos niveis de sindicalização, de filiação partidána, de participação eleitoral ou, de forma geral, de participação da população trabalhadora nos movimentos sociais criticos e reivindicativos.

Não seria este, então, o momento ideal para aprovai-se um conjunto de medidas de política econômica (privatizações, "enxugamento" do Estado, terceirização dos processos produtivos etc.) que permitiriam a continuidade deste processo? Não seria este, então, o monento ideal para a construção de um poder suficientemente forte para enfrentar um

23 Jbdem, p. 32

${ }^{24}$ Embora saiba-se que "a mundialização da economia .. tem acrescido a desigualdade à escala do globo, entre países 'desenvolvidos' (onde $20 \%$ da população consomem $80 \%$ dos produtos) e subdesenvolvidos". Ibdern, p. 34

${ }^{25}$ Tavares. M. C. Tundenciess de Giohalizaçöo, Cirise do lisfado Nacional e sens Impescias sobre o Brasil. Vitória, ANGE, Cademos da ANGE (textos didáticos), j993, n"6. P. 15 
descontentamento social que, mais tempo menos tempo, encontrará canais altemativos de manifestação e pressão? Não estaria o capital se provendo de uma série de instrumentos legais que lhe permitam enfrentar as reivindicaçōes futuras num quadro de legalidade "adequada" que legitime suas açōes?

Qualquer resposta incisiva só poderia ser uma nova indagação. $O$ fato é, no entanto, que "os experimentos neoliberais foram bem sucedidos ali onde uma ou mais das seguintes condições puderam ser satisfeitas: foram iniciados por regimes autoritários; ou por democracias onde as burocracias e o poder executivo gozaram de alto grau de autonomıa porque confinados das pressōes - clientelistas elou corporativistas e dos partidos; ou dispunham de partidos hegemônicos ou quase úni$\cos "{ }^{26}$ Da mesma forma que é "fato notónio que dois dos mass celebrados exemplos de reforma neoliberal, Chile e México, se realizaram mediante regımes fortes e que, neste último caso, mal se iniciou a transıção para um regime politico efetivamente mais aberto" ${ }^{27}$

\section{BIBLIOGRAFIA SUMÁRIA}

AUGE, M. Pow whe Antwopologic des Afondes Contemporains. Paris, Aubjers, 1994

BATISTA, P. N. "O Consenso de Washington: A Visão neolibetal dos Problemas Latiro-Americanos", in BATISTA, P. N. (et al). Em Defeza do Inicresse Nacional. São Paulo. Paz e Tепа, 1995.

BLANC, M. Os Ierdeiros de Danmim. Sảo Paulo, Pägina Aberta. 1994.

BORGES, A \& DRUCK, G. "Crise Global. Terceirização e a Exclusão no Mundo do Trabalho" in Cademos CRH, Salvador, $\mathrm{n}^{n}$ 19, 1993.

CASTEL, R. Les Méromanhores de la Question Sociale. Paris, Fayard. 1995.

${ }^{26}$ Soia. L. "O Dragão enfrenta o Santo", in Folha de São Paulo de 24 de julho de 1994 , p.6 (3).

${ }^{2}$ Batista, P. N. "O Consenso de Washington: A Visão neoliberal dos Problemas Latino-Americanos", in Batista, P. N (et al). Em Defesa do lweresse Nacional São Paulo, Paz e Terra, 1995, p. 107. 
DOS SANTOS, T. "Femando Henrique Cardoso e a T'coria da Dependēncia" in Política e Administracão. Rio de Janeiro, FESPERJ, V.2, $n^{\mathrm{n}} 4,1994$.

DOS SANTOS, T. Economia Mundial. Petrópoles, Vozes, 1994

ELIAS, N. La Société des Individus. Paris, Fayard, $199 \mathrm{I}$.

EWALD, F. L'Etat Providence. Paris, Grasset, 1986

HIRATA, H. Antour du "Modèle" Japonais. Paris, L'Harmattan, 1992.

MALAGUTI, M. L. "A Ideologia do Modelo Japonês de Gestão" in Ensaios FEE. Rio Grande do Sul, n² 2, V. 16, 1995 (no prelo).

MALAGUT, M. L. "A Teoria da Regulação: Dialogando com Karl Marx" in Crise e Regilação (orgs. Mendonça, J. P., Carcanholo, R. \& Nakatani, P.), Vitória, UFES, 1994.

MALAGUT7, M. L. "Teoria da Regulação: Uma Introdução" in Raizes, Campina Grande, UFPB, ñ 9, janejro de 1994.

MALAGUT!, M. L. "Terceirização, Taylorismo e Conflito" in Raizes, Campina Grande, UFPB, $\mathrm{n}^{0}$ 10, dezembro de 1994.

MARQUES-PEREIRA, J. Marche du Travail, Protection, Sociole et Développement à llleure de la Globalisation. Contribuição ao Seminário sobre o Método da Regulação, São Paulo, Fundap, 4-6 de abril de 1995 .

MORIN, E. Terre-Patrie. Paris, Seuil, 1993.

PALLODX, C. La Société Past-Economique: Esquisse d'me Saciété Allemative. Paris, l'Harmattan, 1988.

POLANYI, K. La Grande Transformation. Paris, Gallimard, 1972.

ROSANVALLON, P. La Nouvelle Quesion Saciale: Repenser l'EtatProvidence. Paris, Seuil, 1995.

TAVARES, M. C. Tendèncias de Globalização, Crise do Estado Nacional e seus impactos sobre o Brasil. Cademos da Ange. n 6, Vitória, 1993. 